\title{
COLON
}

\section{Regulation of epidermal growth factor receptor in human colon cancer cell lines by interferon $\alpha$}

\author{
J-L Yang, X-J Qu, P J Russell, D Goldstein
}

Background and aim: The biology of growth factor receptor expression has implications for receptor specific cancer therapy. In this study, we examined: (a) regulation of epidermal growth factor receptor (EGFR) expression in a panel of 10 human colon cancer cell lines using interferon $\alpha$ (IFN- $\alpha$ ); (b) ability of IFN- $\alpha$ to inhibit cell proliferation; and (c) sensitivity of IFN- $\alpha$ pretreated cells to EGF.

See end of article for Methods: Cell proliferation was measured both by crystal violet colorimetric and clonogenic assays. Cell surface, intracellular, and/or total cell protein expression of EGFR was assessed by indirect immunofluorescence flow cytometry and/or fluorescein isothiocyanate (FITC)-EGF binding and internalisation flow cytometric assay.

authors' affiliations

......................

Correspondence to Dr D Goldstein,

Department of Medical

Oncology, Prince of Wales

Hospital, Barker St,

Randwick, Sydney, NSW,

2031, Australia;

d.goldstein@unsw.edu.au

Accepted for publication 5 August 2003
Results: IFN- $\alpha$ treatment upregulated expression of cell surface EGFR in seven of 10 colon cancer cell lines within 16 hours, reaching a peak within 48-96 hours; this was accompanied by transient elevation of intracellular EGFR and marked growth inhibition. IFN- $\alpha$ treated cancer cells were still sensitive to EGF proliferative stimulation.

Conclusions: Our results indicate that cytostatic concentrations of IFN- $\alpha$ can enhance cell surface and intracellular EGFR expression in a proportion of human colon cancer cells. The antiproliferative action of IFN- $\alpha$ could not block the signal transduction of the EGF-EGFR pathway. This may have clinical implications for improving treatment based on targeting of EGFR.
$\mathrm{T}$ he impact of growth factor inhibitors on cancer therapeutics has been limited by the biology of growth factor receptor expression. In the case of the best characterised growth factor receptor, the oestrogen receptor, up to $50 \%$ of breast cancer patients have receptor negative tumours and are thus not eligible for therapy based on binding to this ligand. ${ }^{1}$ Similarly, the HER-2/neu receptor is highly expressed in only $20 \%$ of breast cancers. ${ }^{2}$ This limits the applicability of a highly active and novel therapeutic inhibitor, herceptin, that inhibits HER-2/neu and is now available clinically for the treatment of patients with HER-2-/ neu overexpressing tumours. A similar problem may develop with the use of epidermal growth factor receptor (EGFR) inhibitors currently in advanced stages in clinical trials.

Human EGFR is a member of a family of tyrosine kinase receptors characterised by an extracellular domain with two cytokine rich sequences, and a cytoplasm domain flanked by large hydrophilic tails. It is a transmembrane glycoprotein encoded by the cellular oncogene c-erbB-1, located on chromosome 7. ${ }^{3}$ Following ligand binding, EGFR dimerisation occurs, resulting in high affinity ligand binding, activation of the intrinsic protein tyrosine kinase activity, and tyrosine autophosphorylation. Ligand production by adjacent epithelial and stromal cells normally provides the basic drive for such receptor mediated growth. These events lead to activation of a cascade of biochemical and physiological responses involved in the mitogenic signal transduction of cells. ${ }^{4}$

It has been shown that increased expression of EGFRs is key to enhancing both tumour cell replication and the metastatic phenotype. ${ }^{3}$ The increase in replication is due to both enhanced growth stimulation by external ligand and, in some cases, mutation and autocrine growth enhancement in the absence of external stimulation. ${ }^{5}$ High levels or overexpression of EGFR has thus been associated with aggressive biological behaviour and adverse clinical outcome in various tumour types. ${ }^{6}$
Blockade of EGFR by a monoclonal antibody ${ }^{7}$ or by small molecules that inhibit tyrosine kinase ${ }^{8}$ inhibits cell growth in a dose dependent manner both in vitro in a variety of epithelial cell lines and in vivo in human colon cancer xenografts. Such inhibitors lead to primary growth inhibition and to secondary inhibition of factors associated with promotion of metastasis such as vascular epithelial growth factor expression. ${ }^{9}$ Recently, EGFR inhibitors have been introduced into the clinic. ${ }^{8}{ }^{10-12}$ Effective inhibition is directly related to EGFR expression. One approach in increasing the efficacy of such therapies may be to enhance expression of EFGR. ${ }^{13}$ PD153035 (an EGFR inhibitor) inhibition of tumour growth depends on the numbers of EGFRs expressed, having less activity against cells with lower numbers of EGFR that overexpress HER-2/neu receptor only. ${ }^{14}$

Accumulating evidence suggests that growth factor receptors are modulated not only by their respective ligands but also by other growth factors. A potential growth inhibitory factor is human interferon (IFN). The IFNs are a family of molecules that differ by one or more amino acids. IFN- $\alpha$ is one of three major species of IFNs and possesses antiviral, antiproliferative, and immunomodulatory activities. ${ }^{15}$ Cell cycle retardation, depletion of essential metabolites, and/or modulation of cellular oncogene activity or expression have been suggested as mechanisms for the antiproliferative effects induced by IFN $-\alpha{ }^{15}$

IFN- $\alpha$ can enhance expression of class I HLA-ABC and class II HLA-DP, DQ, and DR antigens as well as of tumour

\footnotetext{
Abbreviations: EGF, epidermal growth factor; EGFR, epidermal growth factor receptor; IFN- $\alpha$, interferon $\alpha$; FCS, fetal calf serum; PBS, phosphate buffered saline; FITC, fluorescein isothiocyanate; MFI, mean fluorescence intensity; IFN $\alpha$ R1, interferon $\alpha$ receptor 1; IFN $\alpha$ R2, interferon $\alpha$ receptor 2 ; JAK, Janus kinases; STAT, signalling transducers and activators of transcription; IRF-1, interferon regulatory factor 1; MAPK, stress dependent mitogen activator protein kinase
} 
associated antigens. ${ }^{13}$ In this respect, it is notable that IFN- $\alpha$ both inhibits human tumour cell growth and upregulates EGFR in primary human epidermoid, cervical, and endometrial tumour cells. ${ }^{13-18}$ In these cell lines, blockade of EGFR by C225, an anti-EGFR inhibitory antibody, was effective following upregulation of EGFR (reviewed by Caraglia and colleagues $\left.{ }^{16}\right)$. Similar studies have demonstrated that IFN- $\alpha$ induced growth inhibition of a human epidermal carcinoma cell is paralleled by upregulation of EGFR that retain their sensitivity to anticancer therapy.

A few studies on the role of IFN- $\alpha$ in regulating EGFR expression have been reported, with variable results, ${ }^{18}$ but none has examined regulation of EGFR expression by IFN- $\alpha$ in colon cancer. In this study, expression of cell surface and intracellular EGFR at different times (0-96 hours) in the presence or absence of IFN- $\alpha$ was measured in a panel of 10 colon cancer cell lines. In addition, the relationship between EGFR levels and the IFN- $\alpha$ induced antiproliferative effect was studied.

\section{MATERIALS AND METHODS \\ Cell lines}

Human colon cancer cell lines, DLD-1, HCT116, HT29, KM12SM, LOVO, SW48, SW480, and SW620 were purchased from the American Type of Cell Culture (Manassas, Virginia, USA). LIM2408 and LIM 2099 were obtained from Dr Robert Whitehead (The Ludwig Institute for Cancer Research, Melbourne, Australia). The cell lines were chosen to ensure that they were derived from sporadic colon cancers and were not hereditary. We identified 10 cell lines in order to ensure that we had a range of baseline EGFR expression to examine.

\section{Cell culture}

Cells were grown in minimum essential medium (Gibco, Grand Island, New York, USA), supplemented with 10\% heat inactivated fetal calf serum (FCS), $2 \mathrm{mM}$ L-glutamine, penicillin, and streptomycin at $37^{\circ} \mathrm{C}$ in a humidified $5 \%$ $\mathrm{CO}_{2}$ and $95 \%$ atmosphere. Cells were fed every 3-4 days, and harvested by brief incubation in $0.02 \%$ EDTA-PBS (ICN, Aurora, Ohio, USA).

\section{Crystal violet colorimetric assay}

Cells were seeded in 24 well plates at $2-5 \times 10^{4}$ cells per well. After 12 hours, different doses $(0,1,10,100,1000$, $10000 \mathrm{IU} / \mathrm{ml})$ of recombinant human IFN- $\alpha$ (2b; a gift from Roche, Products Pty Ltd, Dee Why, NSW, Australia) or EGF (0.01, 0.1, 1, 10, $100 \mathrm{nM}$; Molecular Probes, Leiden, the Netherlands) were added to the medium. For different experiments, selected (optimal) concentrations of IFN- $\alpha$ and/or EGF were used. Cells were washed with DPBS (phosphate buffered saline with divalent cations: $1 \mathrm{mM}$ $\mathrm{CaCl}_{2}$ and $0.5 \mathrm{mM} \mathrm{MgCl}_{2}$; Sigma, St Louis, Missouri, USA) and stained with $0.5 \%$ crystal violet every 24 hours for five consecutive days, rinsed in distilled water until all excess stain had been removed, and finally air dried. Elution solution ( $1: 1 \quad 0.1 \mathrm{M} \mathrm{Na}^{+}$citrate $(\mathrm{pH} \quad 4.2): 100 \%$ ethanol) $1 \mathrm{ml} /$ well was added and mixed gently for 30 minutes before transferring $200 \mu \mathrm{l}$ of the solution from each well into a 96 well plate. Light absorbance of the solution was measured at $540 \mathrm{~nm}$ on the plate reader (Tecan; Grodig, Salzburg, Austria). The growth of experimental and control cells was compared. Duplicate experiments with triplicate samples were performed for all cell lines except LIM2408 where triplicate experiments were done.

\section{Clonogenic growth assay}

Cells were seeded in six well plates (Falcon; Becton Dickinson (BD), Franklin Lakes, New Jersey, USA) at 250300 cells/well. After 12 hours of incubation, different concentrations of IFN- $\alpha$ were added to relevant media and the plates were incubated at $37^{\circ} \mathrm{C}$. Fresh medium containing individual concentrations of IFN- $\alpha$ were exchanged every week. After two weeks of incubation, colonies were stained with $0.5 \%$ crystal violet and manually counted. Colonies ( $>50$ cells) were scored and three replicate wells containing 0-100 colonies/well were counted for each treatment. Duplicate experiments were performed.

\section{Immunofluorescent flow cytometry}

Cells were seeded in $60 \times 15 \mathrm{~mm}$ dishes (Falcon; BD) and treated with $100 \mathrm{IU} / \mathrm{ml}$ of IFN- $\alpha$. Treated and untreated cells were harvested at different time intervals (30 and 60 minutes, 2, 4, 8, 16, 24, 48, 72, and 96 hours) using 0.02\% EDTA in phosphate buffered saline (PBS), washed twice with ice cold PBS, and counted. For detection of intracellular EGFR, cells were resuspended in cold $2 \%$ paraformaldehyde in PBS, microwaved for 15 seconds using $1200 \mathrm{~W}$ to permeabilise the cell membrane, ${ }^{19}$ immediately chilled on ice for 15 minutes, and washed twice with ice cold PBS. The mouse monoclonal antibody against the extracellular domain of human EGFR (catalogue No MO886; Dako (Australia) Pty Ltd, Botany, NSW, Australia) or polyclonal rabbit antibody against the intracellular domain of the EGFR (catalogue No PC98; Oncogene Science Inc, Cambridge, Massachusetts, USA), diluted 1 in 100 in PBS, were added to the cells $\left(1 \times 10^{6}\right.$ cells in $100 \mu$ l volume), while an irrelevant IgG $2 \mathrm{~b}$ was used as the isotype matched antibody control. After 60 minutes on ice, cells were washed and incubated with $100 \mu \mathrm{l}$ of fluorescein isothiocyanate (FITC) conjugated secondary linked antibody, either goat antimouse IgG (catalogue No 81-6511; Zymed, San Francisco, California, USA) or antirabbit IgG (catalogue No 81-6111; Zymed), 1 in 200 dilution in PBS, on ice for 30 minutes in the dark. Cells were then washed twice and resuspended in 1\% formaldehyde in PBS. Cell surface and intracellular immunofluorescence were analysed on a FACSCalibur (BD) using cell Quest software equipped with a $5 \mathrm{~W}$ argon ion laser tuned to $488 \mathrm{~nm}$ at $200 \mathrm{~mW}$. Levels of protein expression were estimated as mean fluorescence intensity (MFI) of anti-EGFR minus that of the isotype matched antibody control. Ten thousand singlet and viable cells of individual treated and control samples were measured. Duplicate experiments with triplicate samples were performed for all cells except LIM2408 where three replicate experiments were used.

Similar methods were used to detect HLA-ABC and HLA-DP, DQ, and DR antigens on the cell surface, with primary antibodies anti-HLA-ABC and anti-HLA-DP, DQ, and DR (Dako) and control antibodies, mouse IgG 2a kappa and mouse IgGl kappa (Sigma Chemical Co.), respectively.

EGF-FITC binding/internalisation and flow cytometry After treatment by $100 \mathrm{IU} / \mathrm{ml}$ of IFN- $\alpha$ for 72 hours, $\sim 80 \%$ confluent cells were washed twice with PBS and continuously cultured in fresh serum free medium for 10 hours at $37^{\circ} \mathrm{C}$. Suspension of cells, harvested with $0.02 \%$ EDTA in PBS, was incubated in serum free medium at $10^{7}$ cells $/ \mathrm{ml}$ with $10^{-8} \mathrm{M}$ EGF-FITC (E-3478; Molecular Probes Inc., Eugene, USA) for various times ( $1,5,15,30$, and 60 minutes) on ice in the dark. Cells treated with unlabelled EGF were used as controls. Triplicate experiments with triplicate specimens in each experiment were performed. The samples were first measured for total EGF bound on the flow cytometer, as above. Subsequently, fluorescence on the cell surface was quenched by adding $1 \mathrm{M}$ HCI to obtain a $\mathrm{pH}$ of 3-4 in the test tube. At this pH, FITC fluorescein was quenched. ${ }^{20}$ Samples were then measured for remaining fluorescence protected from the $\mathrm{pH}$ change (that is, intracellular EGF bound). Quenching and subsequent measurements were performed 
as fast as possible to maintain cellular integrity. During the 1-2 minutes taken, $\sim 90 \%$ cells remained alive, as confirmed by trypan blue exclusion.

\section{Statistical analysis}

Data are presented as mean (SEM) of all replicates, or mean (SD) from all repeated experiments. Spearman's correlation coefficient test was used to analyse the association between EGFR expression and growth inhibition, as well as between EGFR expression and the dose of IFN- $\alpha$. Analysis of variance (ANOVA) and the Scheffe test were used to evaluate nontreated cell growth across/between cell lines following a check for homogeneity of variance by the Levene test. The Kruskal-Wallis and Games-Howell tests were used to detect per cent cell growth/inhibition or per cent changes in EGFR expression across/between cell lines. The paired Student's $t$ test was used to evaluate the significance of protein levels before and after treatment with IFN- $\alpha$. Statistical values of $\mathrm{p}<0.05$ were considered significant. The $\mathrm{p}$ value was for two tailed analysis unless indicated for one tail. Statistical analysis was performed using the SPSS/Winll.0 software (SPSS, Inc, Chicago, Illinois, USA).

\section{RESULTS}

\section{Biological activity of IFN- $\alpha$}

To verify that the IFN- $\alpha$ used was biologically active, specific markers were measured at the same time, including class I HLA-ABC, and class II HLA-DP, DQ, and DR by indirect immunofluorescent flow cytometry. Levels of these markers were all significantly enhanced (paired $t$ test, all $\mathrm{p}<0.01$ ). In particular, HLA-DP, DQ, and DR were raised $>30$-fold on the surface of the target cells 72 hours after the beginning of IFN- $\alpha$ treatment compared with untreated cells (data not shown).

\section{Growth inhibitory effects of IFN- $\alpha$}

To select optimal times for analysis of the relationship between treatment of IFN- $\alpha$ and the effects on cell growth inhibition, the time course of untreated cells was tested over six days (fig lA). From days 2 to 6 , there was a significant difference in cell growth across the cell lines (ANOVA, $\mathrm{F}=3.184, \mathrm{p}=0.005$; Levene, $\mathrm{p}=0.750$ ). Selectively analysing data at 96 hours, a significant difference in growth existed among these cell lines (ANOVA, $\mathrm{F}=53.635, \mathrm{p}<0.001$; Levene, $p=0.409$ ). Compared with SW620 (Scheffé test), the fastest growing cell line at that time, cell lines with similar growth potential were DLDl $(p=0.410)$, HCT116 $(p=0.383)$, and LIM2408 $(p=0.262)$, with slightly lower growth potential of LIM2099 $(\mathrm{p}=0.046)$, and significantly slower growth cell lines (all $p<0.001$ ) HT29, SW48, SW480, KMI2SM, and LOVO. None of the untreated cell lines, except HCT116, reached confluency by day 5 . We then selected day 4 within the linear growth period for different concentration analysis (fig lB) and a five day period for the time course of treated cells (fig $\mathrm{IC}$ ).

The antiproliferative effect of IFN- $\alpha$ on colon cancer cells was dose and time dependent. Firstly, individual cell lines expressed differential sensitivity to different concentrations ( $1-10000 \mathrm{IU} / \mathrm{ml}$ ) of IFN- $\alpha$, with greater growth inhibition in the presence of higher concentrations of IFN- $\alpha$ (fig 1B). Secondly, using the selected dose of IFN- $\alpha$ ( $100 \mathrm{IU} / \mathrm{ml}$, which mimics serum levels achieved in humans treated with subcutaneous interferon) and cells harvested at different time points, the growth inhibitory effects of IFN- $\alpha$ were increased as the duration of culture was increased (fig IC). There was a significant difference in cell responses to 100, 1000 , and $10000 \mathrm{IU} / \mathrm{ml}$ of IFN- $\alpha$ across cell lines (KruskalWallis, $\mathrm{H}=20.398, \mathrm{p}=0.016$ ) and a significant difference in cell responses to $100 \mathrm{IU} / \mathrm{ml}$ of IFN- $\alpha$ from days 2 to 5 across
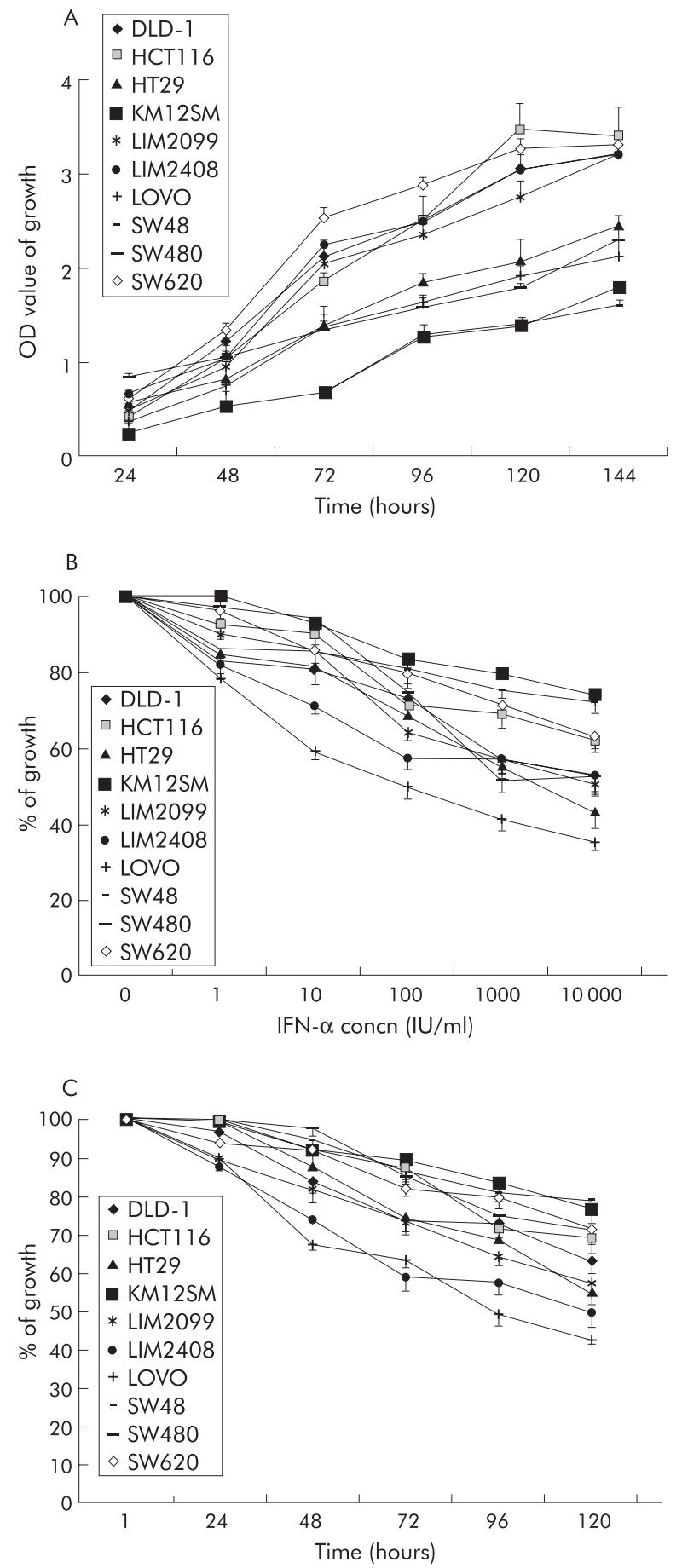

Figure 1 (A) Time course of 10 untreated human colon cancer cell lines as well as (B) dose and (C) time dependent growth inhibitory effects of interferon $\alpha$ (IFN- $\alpha$ ) on these cell lines, evaluated by crystal violet colorimetric assay. Duplicate experiments for all cell lines (except LIM2408, where the experiment was repeated three times) with triplicate samples within each experiment were performed. (A) Mean optical density (OD) values at a wavelength of $540 \mathrm{~nm}$ of untreated cell growth from all replicate samples. Error bars represent SEM. (B) Growth of each cell line at 96 hours after treatment with or without different concentrations (1-10 $000 \mathrm{IU} / \mathrm{ml}$ ) of IFN- $\alpha$. (C) Growth of each cell line at individual time points after treatment with $100 \mathrm{IU} / \mathrm{ml} \mathrm{IFN}-\alpha$ was calculated as a mean percentage of that of untreated controls at the same time point. Error bars indicate the variation in mean percentage of growth from all repeated experiments, which never exceeded 5\%. Cell viability assessed by trypan blue staining was always more than $90 \%$. 


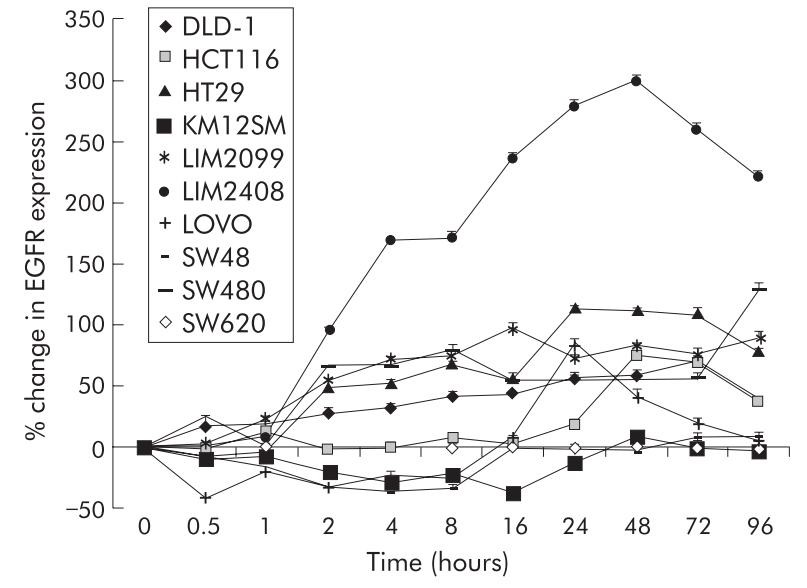

Figure 2 Time dependent epidermal growth factor receptor (EGFR) expression in colon cancer cell lines induced by $100 \mathrm{IU} / \mathrm{ml}$ interferon $\alpha$ and detected by indirect immunofluorescent flow cytometry. Duplicate experiments with triplicate specimens in single experiments were carried out for all cell lines, except LIM2408 where triplicate experiments were performed. The mean per cent change in EGFR expression at individual time points was calculated from the mean fluorescence intensity of treated cell lines versus that of the same cell lines untreated and harvested at the same time. Error bars indicate the variation in mean of all repeated experiments, which was never more than $5 \%$.

the cell lines (Kruskal-Wallis, $\mathrm{H}=23.825, \mathrm{p}=0.005$ ). Cell lines had significantly different sensitivities to $100 \mathrm{IU} / \mathrm{ml}$ IFN- $\alpha$ at 96 hours (Kruskal-Wallis, $\mathrm{H}=28.748, \mathrm{p}=0.001$; Games-Howell, $\mathrm{p} \leqslant 0.001$ between individual cell lines). Sensitivity order from strong to weak were LOVO (49\% of growth), LIM2408 (57\%), LIM2099 (64\%), HT29 (68\%), HCT116 (71\%), DLD-1 (73\%), SW480 (74\%), SW620 (79\%), SW48 $(80 \%)$, and KMI2SM $(83 \%)$. Growth inhibition induced by $1-10000 \mathrm{IU} / \mathrm{ml}$ IFN- $\alpha$ occurred in the absence of evident cytotoxicity, as verified by staining for viability using trypan blue.

We also used the clonogenic assay to further test the sensitivity of colon cancer cell lines to IFN- $\alpha$ over a relatively long culture period (two weeks). There was a significant difference in clone formation using 100, 1000, and $10000 \mathrm{IU} /$ $\mathrm{ml}$ IFN- $\alpha$ across the cell lines (Kruskal-Wallis, $\mathrm{H}=20.398$, $\mathrm{p}=0.016)$. Clone formation in the presence of $100 \mathrm{IU} / \mathrm{ml}$ IFN- $\alpha$ was inhibited by $71 \%$ for LIM $2408,68 \%$ HT29, 57\% LOVO, 48\% SW480, 44\% SW48, 36\% SW620, 35\% DLD-1, 33\% HCT116, 31\% LIM2099, and 28\% KMI2SM. There was a significant difference in response to IFN- $\alpha$ inhibition among these cell lines (Kruskal-Wallis, $\mathrm{H}=28.742, \mathrm{p}=0.001$; Games-Howell, $\mathrm{p} \leqslant 0.002$ between individual cell lines; other data not shown).

\section{Change in EGFR expression after IFN- $\alpha$ treatment}

To evaluate whether IFN- $\alpha$ changed EGFR expression, we performed a live cell immunoassay using the anticell surface EGFR antibody. Under the same experimental conditions, EGFR expression by individual cell lines was at a similar low basic level at different time points $(0,0.5,1,2,4,8,16,24,48$, 72 , and 96 hours) in the absence of IFN- $\alpha$, apart from SW620 which did not express EGFR. After IFN- $\alpha$ treatment, the 10 colon cancer cell lines showed different responses in EGFR expression (fig 2, table 1).

Upregulation of EGFR occurred in all highly IFN- $\alpha$ sensitive cell lines, including LOVO, SW480, DLD-1, HT29, LIM2099, and LIM2408, as well as the HCT116 cell line. The observed enhancement effects were detectable within one hour of treatment with IFN- $\alpha$ in some cell lines, including SW480, DLD-1, LIM2099, HT29, and LIM2408. However, for other cells such as HCT116 and LOVO, the effects were detectable only after 16 hours of IFN- $\alpha$ treatment. Expression of EGFR by these cell lines reached peak levels and was subsequently maintained at higher levels compared with the relevant untreated controls for $\sim 4$ days before falling back (fig 2), and the increased amounts of receptor expression ranged from $70 \%$ to $300 \%$ dependent on the cell line and time point studied (table 1).

In the less sensitive cell lines such as KM12SM and SW48, exposure to IFN $-\alpha$ resulted in slightly reduced and time dependent EGFR expression (fig 2, table 1). Little immunoreactivity of anti-EGFR on the cell surface was noted in untreated and treated SW620 cells. MFI at each time point was close to that of both the isotype and non-treated controls (fig 2, table 1).

There was a significant difference in EGFR expression from 0.5 to 96 hours across the cell lines (Kruskal-Wallis, $\mathrm{H}=61.745, \mathrm{p}<0.001)$. Cell lines showed a significant difference in cell surface EGFR expression at 96 hours (Kruskal-Wallis, $\mathrm{H}=28.712, \mathrm{p}=0.001$; Games-Howell, $\mathrm{p} \leqslant 0.002$ between individual cell lines). EGFR expression from high to low were from cell lines LIM2408 (221\%), SW480 (129\%), LIM2099 (91\%), HT29 (78\%), DLD1 (37\%), HCT116 (37\%), and LOVO (6\%) (table 1).

Treatment of colon cancer cells with IFN- $\alpha$ in the present study did not affect determination of EGFR expression as over $95 \%$ of cell viability was maintained, as evaluated with

Table 1 Relationship between cell surface epidermal growth factor receptor (EGFR) expression and growth inhibition in colon cancer cell lines treated with $100 \mathrm{IU} / \mathrm{ml}$ interferon $\alpha$ (IFN- $\alpha$ )

\begin{tabular}{|c|c|c|c|c|c|c|c|c|}
\hline Cell line & $\begin{array}{l}\text { Peak } \\
\text { time (h) }\end{array}$ & $\begin{array}{l}\text { MFI of EGFR minus } \\
\text { isotype control at } \\
\text { peak time* }\end{array}$ & $\begin{array}{l}\text { Variation in EGFR } \\
v \text { IFN- } \alpha \text { untreated } \\
\text { control at peak } \\
\text { time }(\%)\end{array}$ & $\begin{array}{l}\text { MFI of EGFR } \\
\text { minus isotype } \\
\text { control } \\
\text { at } 96 \mathrm{~h}^{*}\end{array}$ & $\begin{array}{l}\text { Variation in } \\
\text { EGFR } v \text { IFN- } \alpha \\
\text { untreated control } \\
\text { at } 96 \mathrm{~h}(\%) \dagger\end{array}$ & $\begin{array}{l}\text { p Value GFR } v \\
\text { IFN- } \alpha \text { untreated } \\
\text { control } \\
\text { at } 96 \mathrm{~h} \ddagger\end{array}$ & $\begin{array}{l}\text { Maximum growth } \\
\text { inhibition with } \\
\text { IFN- } \alpha \\
\text { at } 96 \mathrm{~h}(\%) \S\end{array}$ & $\begin{array}{l}\mathrm{p} \text { Value IFN- } \alpha \\
\text { treated cell growth } \\
v \text { untreated control } \\
\text { at } 96 \mathrm{~h} \ddagger\end{array}$ \\
\hline LIM2408 & 48 & $29.8(2.7)$ & +300.3 & 24.9 (1.7) & +221.0 & $<0.001$ & 42.5 & 0.015 \\
\hline SW480 & 96 & $26.3(1.4)$ & +147.4 & $26.3(1.4)$ & +129.2 & $<0.001$ & 25.1 & 0.025 \\
\hline LIM2099 & 16 & $23.1(2.4)$ & +128.4 & $22.1(2.7)$ & +90.6 & 0.002 & 35.9 & 0.018 \\
\hline HT29 & 48 & $7.7(0.8)$ & +111.3 & $6.2(0.7)$ & +77.8 & 0.013 & 31.7 & 0.021 \\
\hline LOVO & 24 & $14.4(1.6)$ & +84.8 & $9.3(0.8)$ & +5.5 & 0.297 & 50.5 & 0.003 \\
\hline НCT116 & 48 & 24.9 (3.0) & +75.0 & $10.3(0.5)$ & +36.6 & 0.046 & 28.7 & 0.023 \\
\hline DLD-1 & 72 & $20.3(4.9)$ & +70.7 & $16.3(1.9)$ & +37.4 & 0.033 & 26.9 & 0.024 \\
\hline SW620 & NA & 0 & 0 & 0 & 0 & NA & 20.3 & 0.032 \\
\hline SW48 & 8 & $18.4(3.1)$ & -33.6 & $17.2(3.1)$ & -2.8 & 0.286 & 19.2 & 0.033 \\
\hline $\mathrm{KM} 12 \mathrm{SM}$ & 16 & $9.2(1.8)$ & -36.9 & $8.3(1.5)$ & -2.5 & 0.218 & 16.6 & 0.040 \\
\hline
\end{tabular}

$\mathrm{MFI}$, mean fluorescence intensity; NA, not available.

*Values are mean (SD).

Correlation coefficient (Spearman, $R=0.60, p=0.033$ ) was calculated between data from columns $+($ fig 2$)$ and $\S($ fig $1 C)$.

$\ddagger$ Paired $t$ test was used to compare original quantitative data. 
the trypan blue assay. In addition, we were able to exclude the fact that EGFR upregulation could be ascribed to increases in cell density as untreated cells had higher cell density and lower EGFR levels than the same cells treated with IFN- $\alpha$.

\section{Expression of EGFR in intact cells after IFN- $\alpha$ treatment}

Expression of EGFR in cell surface, intracellular, and complete cell areas was detected by flow cytometry using specific anti-EGFR antibodies or FITC-EGF binding and internalisation assay. Examples of expression of cell surface, intracellular, and/or total EGFR by the EGFR positive cell line (LIM2408) with or without IFN- $\alpha$ treatment are shown in fig $3 \mathrm{~A}$ and $\mathrm{B}$. Using the FITC-EGF binding and internalisation assay, an early (starting from five minutes) and significant increase in EGFR expression was noted in the LIM2408 cell surface (mean (SD) of treated $v$ basic: $35.3(6.5) v 11.5(0.7)$; paired $t$ test, $\mathrm{p}=0.002$ ), intracellular (95.3 (12.1) $v 47.0$ (2.6); $\mathrm{p}=0.001)$, and whole cell (130.7 (17.4) v 58.5 (3.1); $\mathrm{p}=0.001$ ) following IFN- $\alpha$ treatment (fig 3A). Longer observation over 96 hours using immunofluorescent flow cytometry showed that there were also significant increases (paired $t$ test, $\mathrm{p}<0.001$ ) of both cell surface (maximum
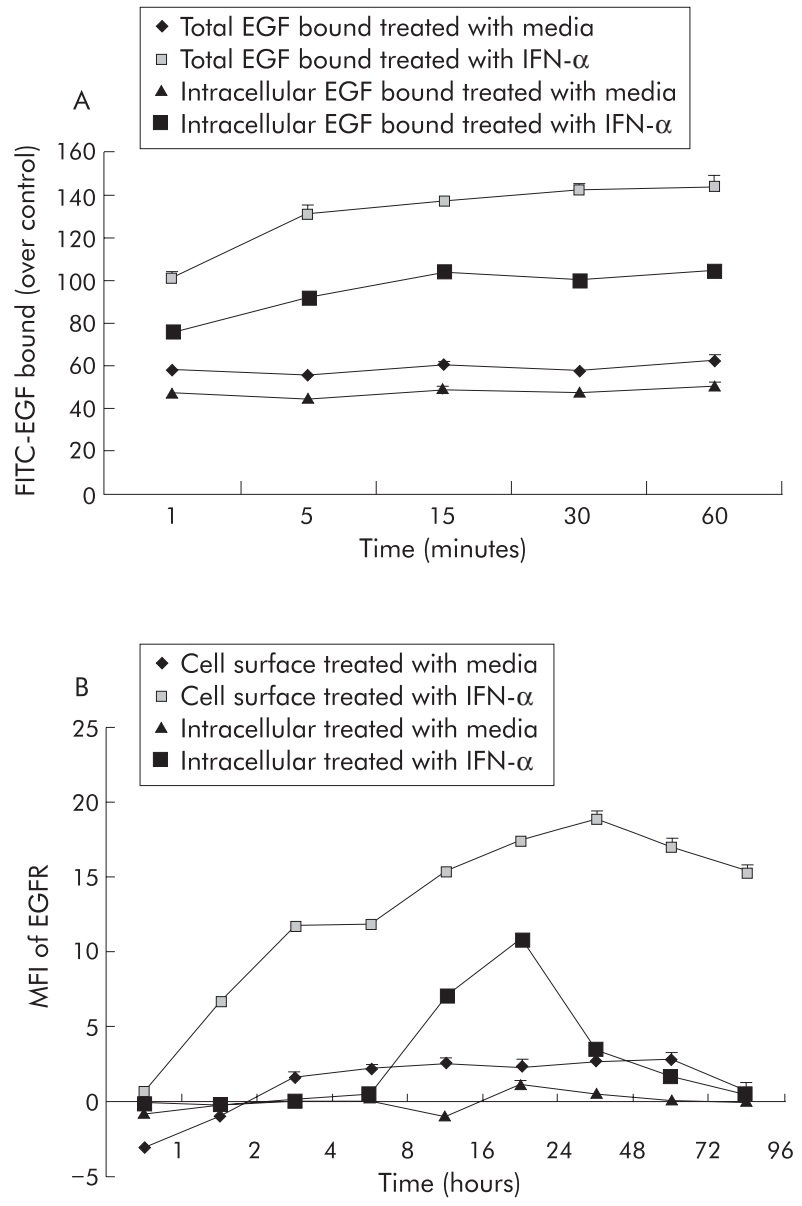

Figure 3 Expression of epidermal growth factor receptor (EGFR) in the total cell, cell surface, and intracellular area of the LIM2408 cell line, with or without treatment with interferon $\alpha$ (IFN- $\alpha 100 \mathrm{IU} / \mathrm{ml}$ ) measured by (A) fluorescein isothiocyanate labelled ligand binding (FITC-EGF) and internalisation and flow cytometric assay with unlabelled EGF as a control or by (B) indirect immunofluorescent flow cytometry using isotype matched irrelevant immunoglobulin as a control. Triplicate experiments with triplicate samples were performed. Data are presented as mean (SEM) fluorescence intensity (MFI) of all replicate samples.
$+712 \%$ ) and intracellular (maximum $+895 \%$ ) EGF receptors following IFN- $\alpha$ treatment, but the intracellular EGFR increase was transient (fig $3 \mathrm{~B}$ ). There was no observable change in EGFR expression before and after IFN- $\alpha$ treatment in SW620 cells, which were EGFR negative.

\section{Relationship between EGFR and IFN- $\alpha$}

The data in table 1 show that the per cent increase in EGFR expression on the surface of individual cell lines induced by IFN- $\alpha$ was paralleled by per cent growth inhibition of individual cell lines. A one tailed significant correlation was confirmed (Spearman's $\mathrm{R}=0.60, \mathrm{p}=0.033$ ) between the increase in EGFR and growth inhibition of the cell lines induced by $100 \mathrm{IU} / \mathrm{ml}$ IFN- $\alpha$ and assessed at 96 hours, with highly increasing EGFR levels being associated with greater antiproliferative effects.

In individual cell lines, the relationship between the increase in EGFR level and dose of IFN- $\alpha$ treatment also correlated well in IFN- $\alpha$ sensitive colon cancer cell lines. For example, fig 4 shows a clear dose dependency in LIM2408 cells, when performed 72 hours after adding IFN- $\alpha$. There was a significant correlation between the increased EGFR and dose of IFN- $\alpha$ (Spearman's $R=0.960, p<0.001$ ). When all EGFR upregulated cell lines were examined as a group, there was still a significant dose response $(R=0.842$, $p<0.001)$. There seemed to be a ceiling effect with little additional benefit over 100 versus 1000 in LIM2408 cells, but this was not consistent across all cell lines as there was a significant difference between 100 and 1000 dosage groups (paired $t$ test, $\mathrm{p}=0.002$ ).

\section{Effects of EGF, IFN- $\alpha$, and EGF plus IFN- $\alpha$ on proliferation of LIM2408 cells}

To determine whether the antiproliferative action of IFN- $\alpha$ could block the function of the EGF-EGFR pathway, the following experiment was performed to determine if growth inhibition of the target cells by IFN- $\alpha$ could be reversed by addition of EGF. LIM2408 cells were precultured with IFN- $\alpha$ ( $100 \mathrm{IU} / \mathrm{ml}$ in medium containing 10\% FCS) for 72 hours, and then $1 \mathrm{nM} / \mathrm{ml}$ EGF was added to the culture. Control groups included (a) media only, (b) media plus EGF, and (c) media plus IFN $-\alpha$ groups. Cell proliferation in the four groups was assessed at different time points following EGF treatment (fig 5). EGF partially reversed IFN- $\alpha$ induced growth retardation in LIM2408 cells at 96 hours, suggesting that the EGF-EGFR pathway was functioning.

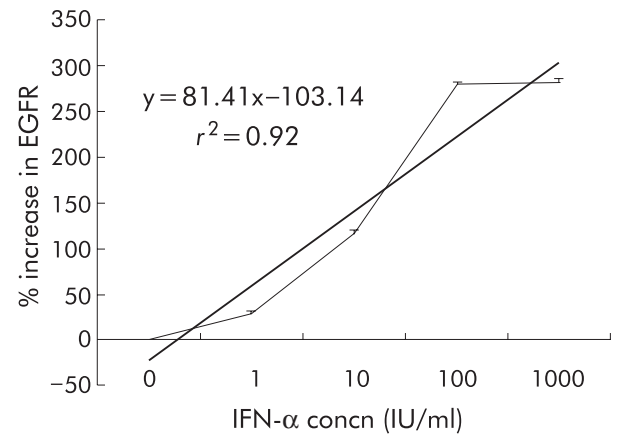

Figure 4 Dose dependent cell surface epidermal growth factor receptor (EGFR) expression in the LIM2408 cell line induced by interferon $\alpha$ (IFN- $\alpha$ ) over 72 hours of cell culture was determined by indirect immunofluorescent flow cytometry. Triplicate experiments using triplicate samples were carried out. The increase in EGFR was expressed as mean percentage of EGFR of that of untreated control cultures. Error bars indicated the variation in all repeated experiments $(<5 \%)$. 


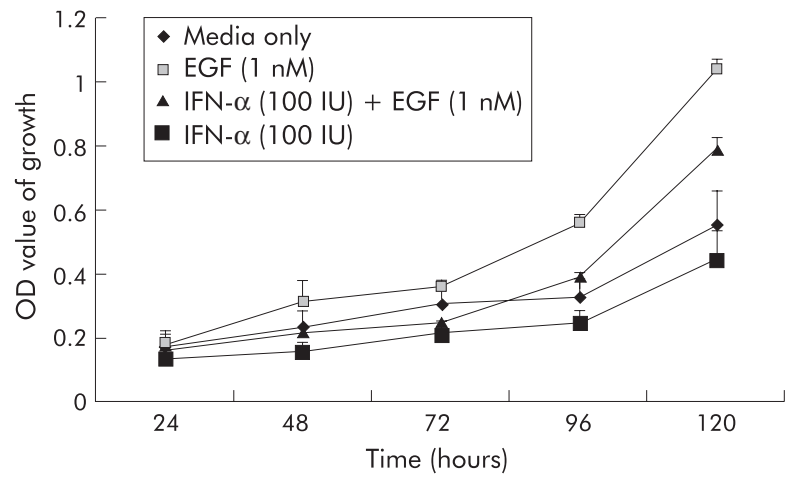

Figure 5 Effects of epidermal growth factor (EGF), interferon $\alpha$ (IFN- $\alpha$ ), and EGF plus IFN- $\alpha$ on proliferation of LIM2408 cells. Triplicate experiments with triplicate samples in each experiment were performed. Optimal concentrations of EGF and/or IFN- $\alpha$ in medium containing 10\% fetal calf serum are shown. These were obtained through a series of pretests. A media only group was included as a control. Cell growth was determined by the crystal violet colorimetric assay and was presented as the mean (SEM) optical density (OD) value at a wavelength of $540 \mathrm{~nm}$.

\section{DISCUSSION}

We have shown that IFN- $\alpha$ used at cytostatic concentrations is associated with transient upregulation of cell surface and intracellular EGFR expression in a proportion of human colon cancer cell lines, concurrent with induction of growth inhibition. This will have implications for modelling in animals and also clinical applications, repeated administration of IFN- $\alpha$ and appropriate timing of EGFR inhibition being important parameters for planning treatment regimens. These data also indicate that upregulation of EGFR does not reverse IFN induced tumour cell inhibition. After addition of EGF in our study, inhibition was partially reversed, suggesting that cytostatic concentrations of IFN- $\alpha$ cannot prevent proliferative stimulation via the EGF-EGFR pathway.

The response of colon cancer cell lines to treatment of IFN- $\alpha$ was not homogeneous. Apart from upregulation of EGFR, downregulation of the receptor and no response were also noted in a few cell lines. Similar effects were determined elsewhere. ${ }^{13182021}$ This may be due to the heterogeneity of tumours and suggests that regulation of EGFR expression in response to IFN- $\alpha$ is complicated.

Consistent with our findings, other studies have confirmed that cytostatic concentrations of IFN- $\alpha$ do not depress and may even potentiate EGFR function when inducing growth inhibition in the target tumour cells investigated. ${ }^{16-18}$ At the same time, the EGF-EGFR pathway remains responsive as external EGF can partially reverse the growth inhibition of IFN- $\alpha$ and anti-EGFR antibody can enhance inhibition of tumour cell growth induced by IFN- $\alpha .{ }^{16}$

Despite intensive investigation, the signal events by which binding of peptide factors to plasma membrane receptors activate gene transcription and cell growth regulation remain largely undefined. EGF can exert its effects through binding to EGFR on the cell surface, followed by activation of intrinsic protein kinase activity to stimulate proliferation of tumour cells. ${ }^{22}$ Based on this, it has been speculated that a mechanism to explain the growth inhibitory effects induced by IFN- $\alpha$ in human tumour cells is downregulation of EGFR expression and/or desensitisation to growth promoting intracellular pathways induced by EGF.22 ${ }^{23}$ However, our study and many others have demonstrated that IFN- $\alpha$ at cytostatic concentrations can both enhance EGFR expression and induce growth inhibition in most EGFR positive tumour cell lines detected, but not in EGFR negative cell lines (for example, SW620). These data suggest that the growth inhibitory effect of IFN- $\alpha$ on human tumour cells may have two alternative explanations. It could occur via blockade of some component of the EGF stimulated mitogenic pathway, with compensatory EGFR upregulation because of the reduced effect of EGF in the presence of interferon. Alternatively, the two effects may be entirely unrelated, with independent upregulation of the EGF pathway in response to the cytostatic effect of interferon on an entirely different pathway, leading to growth inhibition unrelated to the EGFEGFR pathway.

Upregulation of EGFR induced by IFN- $\alpha$ could be a direct and regulatory effect of IFN- $\alpha$ on EGFR synthesis and function or a secondary effect via changes induced in cell growth status. Rubinstein and colleagues ${ }^{24}$ reported that IFN- $\alpha$ induced expression of interferon regulatory factor 1 (IRF-1), an important transcription factor that modulates expression of many IFN inducible genes, including EGFR. IRF-1 induces EGFR promoter activity up to 200-fold compared with 3-10-fold induced by other regulators, including SP1, AP2, p53, WT1, and GCF. Apart from this direct effect, the timing of IFN- $\alpha$ induction of upregulation of EGFR in our study and others suggests that upregulation of EGFR may be a secondary effect. A possible working hypothesis suggested by Budillon and colleagues $^{13}$ and Caraglia and colleagues ${ }^{25}$ is that increased receptor expression could be part of a homeostatic cellular response to heavy antiproliferative stimuli. This hypothesis correlates well with other observations that growth inhibition induced by different agents is accompanied by EGFR upregulation. ${ }^{26}{ }^{27}$

An alternative hypothesis for the mechanism of growth inhibition by IFNs and an indirect interaction with the EGF pathway may be through other pathways such as the JAKSTAT (Janus kinases-signalling transducers and activators of transcription) and MAPK (stress dependent mitogen activator protein kinase) pathways. ${ }^{28}$ IFNs utilise the JAK-STAT pathway from the interferon receptor (IFN $\alpha \mathrm{Rl}$ and IFN $\alpha \mathrm{R} 2^{29}$ ) and certain subtypes of STATS are associated with growth inhibition, identifying an entirely non-EGF mediated pathway of growth inhibition. ${ }^{30-33}$ Alternatively, a more complex relationship between the JAK-STAT pathway and the EGFR intrinsic tyrosine kinase pathway may lead to synergistic growth inhibitory effects. ${ }^{34} 35$

Whatever the mechanism, our study indicates an opportunity for enhancing the growth inhibition of EGFR blockers. An exponential relationship between levels of EGFR overexpression and the growth inhibitory effects of an EGFR inhibitor, PD153035, has been described in many cell lines from vulvar squamous carcinoma, breast adenocarcinoma, colon adenocarcinoma, prostate adenocarcinoma, and cervical squamous carcinoma. ${ }^{14}$ Colon cancers have generally been shown to have increased expression of EGFRs ${ }^{36}$ and studies of the effects of EGFR inhibitors in humans with colorectal cancer have begun. ${ }^{37}$ A growth inhibitory drug that secondarily enhances EGF receptor expression may increase the susceptibility of such cells to combined inhibition.

In conclusion, our studies suggest that, at least in colon cancer cell lines, the antiproliferative effects of IFN- $\alpha$ are accompanied by upregulation of EGFR in EGFR positive cell lines. Furthermore, the increased EGFR expression noted at the cell surface remains sensitive to EGF stimulation, as reported in this paper and also in several other studies. Therefore, the combination of IFN- $\alpha$ with the new class of anticancer agents, EGFR inhibitors, may lead to enhanced antiproliferative activity. Study of this potential interaction is currently underway.

\section{Authors' affiliations}

J-L Yang, Department of Surgery, Prince of Wales Hospital, University of New South Wales, Sydney, Australia 
X-J Qu, Department of Pharmacology, Institute of Materia Medica, Shandong Academy of Medical Sciences, Jinan, P R China

P J Russell, Oncology Research Centre, Prince of Wales Hospital, University of New South Wales, Sydney, Australia

D Goldstein, Department of Medical Oncology, Prince of Wales

Hospital, University of New South Wales, Sydney, Australia

\section{REFERENCES}

1 Elledge RM, Fuqua SAW. Estrogen and progesterone receptors. In: Harris JR, Lippman ME, Morrow M, et al, eds. Diseases of the breast, 2nd edn. Philadelphia: Lippincott, Williams and Wilkins, 2000:471.

2 Paik S, Hazan R, Fisher ER, et al. Pathological findings from the National Surgical Adjuvant Breast and Bowel Project: prognostic significance of erbB-2 protein overexpression in primary breast cancer. J Clin Oncol 1990:8:103-12.

3 Srivastava A, Alexander J, Lomakin I, et al. Immunohistochemical expression of transforming growth factor- $\alpha$ and epidermal growth factor receptor in pancreatic endocrine tumours. Hum Pathol 2001;32:1184-9.

4 Carpenter G, Cohen S. Epidermal growth factor. J Biol Chem 1990;265:7709-12.

5 Ge H, Gong X, Tang C-K. Evidence of high incidence of EGFR VIII expression and coexpression with EGFR in human invasive breast cancer by laser capture micro-dissection and immunohistochemical analysis. Int J Cancer 2002;98:357-61.

6 Grandis JR, Melhem MF, Gooding W E, et al. Levels of TGF- $\alpha$ and EGFR protein in head and neck squamous cell carcinoma and patient survival. J Natl Cancer Inst 1998;90:824-32.

7 Mendelsohn J. Epidermal growth factor receptor inhibition by a monoclonal antibody as anticancer therapy. Clin Cancer Res 1997:3:2703-7.

8 Ciardiello F, Tortora G. A novel approach in the treatment of cancer: Targeting the epidermal growth factor receptor. Clin Cancer Res 2001; 7:2958-70

9 Ciardiello $F$, Caputo R, Bianco R, et al. Inhibition of growth factor production and angiogenesis in human cancer cells by Z.D 1839 (Iressa), a selective epidermal growth factor receptor tyrosine kinase inhibitor. Clin Cancer Res 2001;7:1459-65

10 Ciardiello F, Caputo R, Bianco R, et al. Antitumour effect and potentiation of cytoxic drugs activity in human cancer cells by ZD-1839 (Iressa), an epidermal growth factor receptor-selective tyrosine inhibitor. Clin Cancer Res $2001 ; 6: 2053-63$

11 Lichtner RB, Menrad A, Sommer A, et al. Signaling-inactive epidermal growth factor receptor/ligand complexs in intact carcinoma cells by quinazoline tyrosine kinase inhibitors. Cancer Res 2001:61:5790-5.

12 Sewell JM, Macleod KG, Ritchie A, et al. Targeting the EGF receptor in ovarian cancer with the tyrosine kinase inhibitor ZD 1839 ("Iressa"). Br J Cancer 2002;86:456-62.

13 Budillon A, Tagliaferri P, Caraglia M, et al. Upregulation of epidermal growth factor receptor induced by $\alpha$-interferon in human epidermoid cancer cells. Cancer Res 1991;51:1294-9.

14 Bos M, Medelsohn J, Kim Y-M, et al. PD153035, a tyrosine kinase inhibitor, prevents epidermal growth factor receptor activation and inhibits growth of cancer cells in a receptor number-dependent manner. Clin Cancer Res 1997;3:2099-106.

15 Pryor K, Stricker P, Russell P, et al. Antiproliferative effects of bacillus calmetteguerin and interferon- $\alpha 2 b$ on human bladder cancer cells in vitro. Cancer Immunol Immunother 1995:4:309-16.

16 Caraglia M, Leard A, Corradino S, et al. Alpha-interferon potentiates epidermal growth factor receptor-mediated effects on human epidermoid carcinoma KB cells. Int J Cancer 1995;61:342-7.

17 Heise H, Depenbrock H, Rastetter JW, et al. Characterization and mutual ligand-induced modulation of epidermal growth factor and interferon-alpha receptor on renal carcinoma cells in vitro. Anti Cancer Drugs 1995;6:686-92.

18 Scambia G, Panici P B, Ferrandina G, et al. Effect of recombinant human interferon-alpha/ $2 \mathrm{~b}$ on epidermal-growth-factor-estrogen and progesterone-receptor expression in primary cervical cancer. Int J Cancer 1994;58:769-73.

19 Larsen J-K. Measurement of cytoplasmic and nuclear antigens. In: Ormerod MG, ed. Flow cytometry, 3rd edn. Oxford: Oxford University Press, 2000:33-58.

20 Mueller H, Loop P, Liu R, et al. Differential signal transduction of epidermalgrowth-factor receptors in hormone-dependent and hormone-independent human breast cancer cells. Eur J Biochem 1994;221:631-7.

21 Scambia G, Panici PB, Battaglia F, et al. Effect of recombinant human interferon-alpha $2 b$ on receptors for steroid hormones and epidermal growth factor in patients with endometrial cancer. Eur J Cancer 1991;27:51-3.

22 Fish EN, Ghislain J, Trogadis J, et al. Inhibitory effects of $\alpha$-interferon on epidermal growth factor-mediated receptor-dependent events. Cancer Res 1993;53:5148-57.

23 Fan Z, Shang BY, Lu Y, et al. Reciprocal changes in p27(kip 1) and p21 (cipl) in growth inhibition mediated by blockade or overstimulation of epidermal growth factor receptors. Clin Cancer Res 1997;3:1943-8.

24 Rubinstein YR, Proctor KN, Bergel M, et al. Interferon regulatory factor-1 is a major regulator of epidermal growth factor receptor gene expression. FEBS Letters 1998;431:268-72.

25 Caraglia M, Abbruzzese A, Leardi A, et al. Interferon-alpha induces apoptosis in human $\mathrm{KB}$ cells through a stress-dependent mitogen activated protein kinase pathway that is antagonized by epidermal growth factor. Cell Death Differ 1999;6:773-80.

26 Caraglia M, Tagliaferri $P$, Correale $P$, et al. Cytosine arabinoside increases the binding of ${ }^{125}$-labelled epidermal growth factor and ${ }^{125}$-transferrin and enhances the in vitro targeting of human tumour cells with anti-(growth factor receptor) mAb. Cancer Immunol Immunother 1993;37:150-6.

27 Caraglia M. Pinto A, Correale $\mathrm{P}$, et al. 5-Aza-2'-deoxycytidine induces growth inhibition and upregulation of epidermal growth factor receptor on human epithelial cancer cells. Ann Oncol 1994;5:269-76.

28 Velichko S, Wagner TC, Turkson J, et al. STAT3 activation by type I interferons is dependent on specific tyrosines located in the cytoplasmic domain of interferon receptor chain 2c. Activation of multiple STATS proceeds through the redundant usage of two tyrosine residues. J Biol Chem 2002;277:35635-41

29 Chill JH, Nivasch R, Levy R, et al. The human interferon receptor: NMR-based modelling, mapping of the IFN-alpha 2 binding site, and observed ligandinduced tightening. Biochem 2002;41:3575-85.

30 Saharinen $\mathrm{P}$, Vihinen $M$, Silvennoinen $O$. Autoregulation of the Jak2 tyrosine kinase. Proceedings of the 94th Annual Meeting of the American Association for Cancer Research (Toronto Version) 2003;1347:306.

31 Gotoh B, Komatsu T, Takeuchi K, et al. Paramyxovirus strategies for evading the interferon response. Rev Med Virol 2002;12:337-57.

32 Zhang ZJ, Muhr C, Wang JL. Interferon-alpha inhibits the DNA synthesis induced by PDGF and EGF in cultured meningioma cells. Anticancer Res 1996;16:717-23.

33 Chin YE, Kitagawa M, Kuida K, et al. Activation of the STAT signaling pathway can cause expression of caspass 1 and apoptosis. Mol Cell Bio 1997; 17:5328-37.

34 Leaman DW, Pisharody S, Flicking TW, et al. Roles of JAKs in activation of STATs and stimulation of c-fos gene expression by epidermal growth factor. Mol Cell Biol 1996; 16:369-75.

35 David $M$, Wong L, Flavell R, et al. STAT activation by epidermal growth factor (EGF) and amphiregulin. Requirement for the EGF receptor kinase but not for tyrosine phosphorylation sites or JAK1. J Biol Chem 1996;271:9185-8.

36 Goldstein NS, Armin M. Epidermal growth factor immunohistochemical reactivity in patients with American Joint Committee on cancer stage colon adenocarcinoma: implications for a standardised scoring system. Cancer $2001 ; 92: 1331-46$.

37 Baselga J, Rischin D, Ranson $M$, et al. Phase I safety, pharmacokinetic, and pharmacodynamic trial of ZD1839, a selective oral epidermal growth factor receptor tyrosine kinase inhibitor, in patients with five selected solid tumour types. J Clin Oncol 2002;20:4276-8. 